\title{
Stakeholders and their view on forest-based bioeconomy in Slovakia
}

\author{
Lenka Navrátilová*, Jozef Výboštok, Jaroslav Šálka \\ Technical University in Zvolen, Faculty of Forestry, T. G. Masaryka 24, SK-960 01 Zvolen, Slovak Republic
}

\begin{abstract}
Within the concept of bioeconomy at Slovak level, forestry is often seen as a key sector. For that reason, the concept of forest-based bioeconomy gained a specific importance. To this concept is on the European level already paid increasing attention not only in research, but also in politics. Whether or not the forest-based bioeconomy will have a success in Slovakia is greatly dependent on stakeholders' perception and attitude towards the concept. Therefore, the objective of this paper is to identify stakeholders' perception of forest-based bioeconomy. To achieve this, we identified 13 stakeholders from various, bioeconomy-related, sectors that were suitable for qualitative interviewing. The respondents are representants of public and private organizations and are active in relevant areas. The study was conducted using structured interview consisting of 12 questions. Respondents in general tend to lean towards forest-based bioeconomy, as they feel that it brings more opportunities (for the forest and wood-processing sector, economy, industry, nature protection) than risks. However, a threat has presented itself during the study, being the fact that forest stakeholders do not feel to be sufficiently involved in bioeconomy discussion. For the bioeconomy to fulfil its role as an all-purpose weapon, there is an urgent need for more precise policy guidance and for involving of all relevant stakeholders into discussion.
\end{abstract}

Key words: stakeholders; bioeconomy; forest-based bioeconomy; perception; interview

Editor: Zuzana Sarvašová

\section{Introduction}

For a successful bioeconomy implementation on both national and European level, involvement of all relevant stakeholders into discussion is necessary (EC 2018; Zeug et al. 2019). The emphasis on the development of the forest-based bioeconomy requires a more balanced approach to the economic, environmental and social aspects of the bioeconomy.

Bioeconomy is a multi-disciplinary approach (EC, 2012) tackling various global challenges (such as overpopulation, climate change, ecosystem degradation, poverty, etc.) in which forest sector has a particular importance, as forest (together with agricultural) landscapes are seen as an important biomass resource (Böcher et al. 2020) on national and European level. The forest sector, as a producer of various resources, materials, and services, has the potential to help in societal transformation towards more sustainable development. Also, the ability of forests and forest-based products to sequester carbon is seen as a great contribution to climate change mitigation (Parobek et al. 2019; Paluš et al. 2021). For that reason, a concept of forest-based bioeconomy emerged from the concept of bioeconomy. Forest-based bioeconomy is a branch of bioeconomy using primarily forest resources in production processes which causes the substitution of products, materials and services based on fossil resources by products, materials and services based on natural (forest) resources (Wolfslehner et al. 2016).

An open and informed dialogue on complex topics such as bioeconomy (and forest-based bioeconomy) and the involvement of different groups of stakeholders and the general public can bring the concept of the bioeconomy (and forest-based bioeconomy) closer to society. Involvement of all stakeholders and the public are key elements in the development of EU policy as well as in relevant research and innovation. Forest-related policies at the EU level are able to set the boundaries of future forest management, yet national stakeholders feel their voice is not being heard when it comes to development of EU policies (Aggestam et al. 2017). The point was also previously made by McCormick and Kautto (2013) who demand involvement of public and relevant stakeholders in an open discussion creating participatory governance. Getting the insight from all relevant stakeholders can be helpful while focusing on solving the societal problems related to bioeconomy transformation keeping in mind transparency, multi-perspective and innovations (Gerdes et al. 2018; Bezama 2018; Kircher et al. 2018). 
Although increasing number of national bioeconomy strategies occurs at the European and global level, the integrated strategies, action plans or devoted institutions are still lacking (Kleinschmit et al. 2017; German Bioeconomy Council 2018; Bell et al. 2018). Meeting the demand for participatory approach, most of the developed policy strategies are starting to engage more stakeholders by means of various conferences, workshops, surveys etc. (German Bioeconomy Council 2018). However, these efforts might not be enough. Bringing the stakeholders together requires strategic and systematic approach, creating activities at national/regional level, such as policy debates (EC 2018; Gerdes et al. 2018). To increase engagement of stakeholders is also possible by ensuring policy relevance of these conferences and workshops in a way that links discussed topics to current political debates (Gerdes et al. 2018).

Engagement of all relevant stakeholders into, not only, bioeconomy discussion clearly is a necessity, but it will not do without its challenges. Researchers have identified countries in which stakeholders' involvement proved to be exceptionally problematic due to the fact that stakeholders themselves are not used to being a part of policy-making process or they do not feel to be heard. Socialist history of Slovakia is what makes the participatory governance difficult, as there is lack of traditions and institutional arrangements for stakeholder empowerment (Lazdinis et al. 2005; Makrickiene et al. 2019). Therefore, when developing engagement tools, the local "culture of participation" should be accounted for (Gerdes et al. 2018).

What is also important when it comes to stakeholders' involvement into bioeconomy discussion is their perception of the concept. Growing number of studies occurs. Countries such as Finland, Sweden, Austria or Germany are already investigating bioeconomy perception by forest stakeholders (Pülzl et al. 2017). Swedish forest sector proved to be accepting of the concept of bioeconomy as it's perceived as a natural expansion of the Swedish forestry model (Hodge et al. 2017). A similar research was conducted in Germany (Stein 2017) analysing the acceptance of bioeconomy by German forest and wood-processing sector. In this study, bioeconomy was also identified as a broadly accepted concept. Zeug et al. (2019) focused on investigating German stakeholders' perception of bioeconomy monitoring through different method using the sustainable development goal framework. In this study, similarities were found regarding the importance of some sustainable development goals, however stakeholders' perspectives proved to be motivated by specific means of achieving specific ends based on their values (Zeug et al. 2019). Forest stakeholders in general tend to feel as a backbone of bioeconomy, yet only in few national strategies (with the exception of forest-rich countries) they have been involved or consulted (Pülzl et al. 2017). The same was previously proved by Davies et al. (2016) who found out that when it comes to bioeconomy development, it is not usual for stakeholders to engage in participatory governance.

To this date, no explicit bioeconomy (or forest-based bioeconomy) strategy has been published in Slovakia. Bioeconomy in Slovakia is therefore governed through various bioeconomy-related sectoral strategies, such as forestry, energy, environment, agriculture, rural development, innovation, etc. When it comes to forest sector, state forestry and environmental authorities strongly influence the decision-making process, which subsequently form the demand for forest management (Sarvašová et al. 2013; Brodrechtová et al. 2018). Furthermore, in 2020 a strategy was published that is considered to be the foundation of national bioeconomy, called the Low-Carbon Development Strategy of the Slovak Republic until 2030 with a View to 2050 . Even though, this strategy does have a cross-sectoral character (same as bioeconomy) and address bioeconomyrelated problems, the term itself is not defined within the strategy. Publishing of this strategy is seen as proof that Slovakia respects and implement European regulation into national legislative (Navrátilová et al. 2021). Assessing the bioeconomy potential in Slovakia, regarding the natural conditions and public opinion, the bioeconomy potential is significant, yet still remaining untapped (EC 2018; Parobek et al. 2019; Navrátilová et al. 2020). With this in regard to, Slovakia is planning on developing a bioeconomy dedicated strategy in the near future (EC 2018).

This paper is focused on bioeconomy stakeholders in Slovakia and their perception of the role of forest and wood-processing sector within bioeconomy. We paid our attention to stakeholders from relevant sectors (not only forest and wood-processing sector) - energy, forestry, nature protection, research, and forest and wood industry. The aim of the paper is not only to identify how bioeconomy-relevant stakeholders in Slovakia perceive the concept of bioeconomy, but also to explore the perceived relationship between bioeconomy and forest and wood-processing sector in Slovakia.

\section{Materials and methods}

Data collection was conducted through qualitative research using structured interview with carefully composed group consisting of relevant actors active in the bioeconomy-related fields. Data were collected in the form of a personal or telephone conversation, or via email. The data were collected between October 2019 - February 2020 and the duration of respective interviews is very individual, as it depends on the respective stakeholders (ranging from 15 minutes to 1.5 hours). The interview consists of answers to pre-prepared questions that are available to the respondent well in advance. The interview was developed in cooperation with international EFI project Perceiving the Forest-based Bioeconomy (PerForm) and consists of 12 questions. With the permission 
from respondents the interviews are being recorded and later transcribed. We selected 7 questions which are analysed in the paper as we found them to be of the highest importance for the study. The analysed questions of the interview are displayed in the Table 1 . The methodology of this study is based on Hodge et al. (2017), as we also aimed to identify the interpretation of bioeconomy, the role of forestry in bioeconomy, and perceived risks and opportunities related to bioeconomy.

Identification and selection of stakeholders is performed in two steps:

1. Map all related actors (public and private) - representatives of bioeconomy-related public and private organizations. The sample includes representatives from governmental bodies, industry, research, and other interest organizations (e.g. NGOs, consultancies).

1. Select a representative sample from mapped bioeconomy-related stakeholders group - to select a good sample of representatives, two main criteria are followed:

- Stakeholders are (or were recently) active within the forest-based sector, or other related sectors working closely with the forest-based sector and/ or using wood-based raw materials, products and services

- Stakeholders are (or were recently) associated with bioeconomy, e.g. in a form of public statements, lectures, conferences, press releases, scientific publications etc.

As Slovakia is a country that does not have a specifically defined area of bioeconomy, our sample consists of representatives of related sectors. The list and characteristic of the sample is displayed in the Table 2, while the identity of our respondents stays anonymous. The respondents were divided into groups according to char- acter of their institution, each group is displayed in different colour (also displayed in the Table 2).

The analyses were focused on the respondents' relations to individual questions, setting the scale from strongly agree (SA) to strongly disagree (SD), while ambiguous answers were considered neutral. Subsequently, the results were displayed using the R studio program, as it is a suitable method for results visualization (RStudio Team, 2020).

\section{Results}

The results of conducted analyses are displayed in the Fig. 1. Most of our respondents are not only aware of bioeconomy, but they also understand the concept. In the detail, 7 respondents (PEFC, TU, NFC, BC, FSR, KRON, NP) have a very good understanding of the topic, 6 respondents (MA, SEA, AP, SLOV, ME, ACPFO) have a good understanding and an understating of 1 respondent (SFC) remains at neutral level.

When it comes to forest and wood-processing sector, the majority of respondents (TU, PEFC, NFC, KRON, SLOV, ME, MA, SEA, BC, ACPFO) strongly agree bioeconomy development will bring opportunities to these sectors, while 3 respondents (SFC, FSR, AP) agree with this and 1 respondent remains neutral (NP). 3 respondents (BC, KRON, FSR) do not see any risks related to bioeconomy development for forest and wood-processing sector, while another 3 respondents remain neutral (PEFC, NFC, AP). On the other hand, 3 respondents (SFC, TU, ACPFO) agree that bioeconomy development will be also risky for these sectors and 5 respondents (ME, SEA, SLOV, NP, MA) strongly agree with this.

Only 3 respondents (MA, NFC, BC) feel to be strongly involved in the development of bioeconomy strategy, 2

Table 1. Questions analysed in the study.

\begin{tabular}{ll}
\hline Number of questions & \multicolumn{1}{c}{ Questions } \\
\hline Q1 & What do you understand by bioeconomy? \\
Q2 & Does bioeconomy bring new opportunities to the forestry and wood-processing sector? \\
Q3 & Does bioeconomy bring risks to the forestry and wood-processing sector? \\
Q4 & Are you involved in the development of the bioeconomy strategy? \\
Q5 & Does the policy framework for the forest and wood-processing sector need to change in order for it to participate in the bioeconomy development? \\
Q6 & Is your organization involved in negotiating these policy framework changes? \\
Q7 & Are the stakeholders from the forest and wood-processing sector sufficiently involved in national discussions about bioeconomy development? \\
\hline
\end{tabular}

Table 2. List of interviewed organisations.

\begin{tabular}{llc}
\hline Organization & & \multicolumn{1}{c}{ Characteristic } \\
\hline Bioeconomy Cluster & non-governmental organisation & Abbreviation \\
Slovak Environment Agency & governmental environmental body & BC \\
Ministry of agriculture and rural development of SR & government & SEA \\
Slovak Forestry Chamber & forestry institution & MA \\
Slovwood Ružomberok & wood-processing industry & SFC \\
Kronospan & wood-processing industry & SLOV \\
Apertis & energy counselling & KRON \\
National Nature Protection & governmental nature protection body & AP \\
Forests of the Slovak Republic & forest enterprise & NP \\
PEFC Slovakia & non-governmental organisation & FSR \\
Technical University in Zvolen & forestry university & PEFC \\
National Forest Centre & forestry research & TU \\
Ministry of Environment of the SR & government & NFC \\
Association of Community and Private Forests Owners of the Banská Bystrica Region & forest owners association & ME \\
& & \\
\hline
\end{tabular}


respondents (NP, ME) feel to be involved, 1 respondent remain neutral (SLOV), another one respondent does not feel to be involved (ACPFO) and 7 respondents (SFC, FSR, SEA, KRON, PEFC, AP, TU) feel strongly that they are not involved in these activities.

Analysing another question, 6 respondents (SEA, NP, NFC, FSR, PEFC, SLOV) strongly agree that change in forest policy framework is needed so that it enhances its participation in bioeconomy development at national level. Additional 4 respondents agrees (SFC, AP, KRON, $\mathrm{ACPFO}$ ) and 3 respondents disagree (ME, MA, BC) with this and 1 respondent strongly disagrees with this (TU).

When it comes to negotiating these changes, 4 respondents (MA, ME, BC, NFC) feel to be strongly involved, 5 respondents (PEFC, KRON, FSR, AP, NP) feel to be involved and 5 respondents (SLOV, SEA, TU, SFC, ACPFO) strongly feel that they are not involved in these activities.

Results of the last analysed question show that only 2 respondents (MA, BC) strongly agree that forestry stakeholders are involved in national bioeconomy discussion, 1 respondent (KRON) agrees with this, 3 respondents (NP, ME, ACPFO) remain neutral. The majority of respondents do not agree that forestry stakeholders are sufficiently involved in these discussion, as equal number of respondents disagree (SEA, AP, NFC, TU) and strongly disagree (SFC, SLOV, FSR, PEFC) in this matter.

\section{Discussion}

All of our respondents are aware of the concept of bioeconomy, while the vast majority of respondents also show a good understanding of the concept. Good understanding of the concept is a prerequisite for gaining relevant information in this research. Bioeconomy is often referred to as a window of opportunities predominantly for the forest and wood-processing sector (Wolfslehner et al. 2016). This also proves to be the fact in our study, where the vast majority of respondents think that bioeconomy will bring new opportunities for forest and wood-processing sector. The main opportunities that are identified by our respondents are economic growth in general and also regarding forest and wood-processing sector emerging from increased promotion of the sector. As an important opportunity brought by bioeconomy development are seen socio-economic benefits by creating new job opportunities, value added and employment for marginalized social groups of Slovak citizens. Furthermore, improved forest management is acknowledged as a bioeconomy-related opportunity by more efficient biomass utilisation and more sustainable management of natural resources. Efficient biomass use is connected with another identified opportunity being promotion of biomass use not only in industry, but also in energy and everyday life. Bioeconomy development in Slovakia also offers an opportunity for maintenance of infrastructure and other objects needed for sustainable management of forest and wood-processing sector. Moreover, the interviewed stakeholders see bioeconomy development

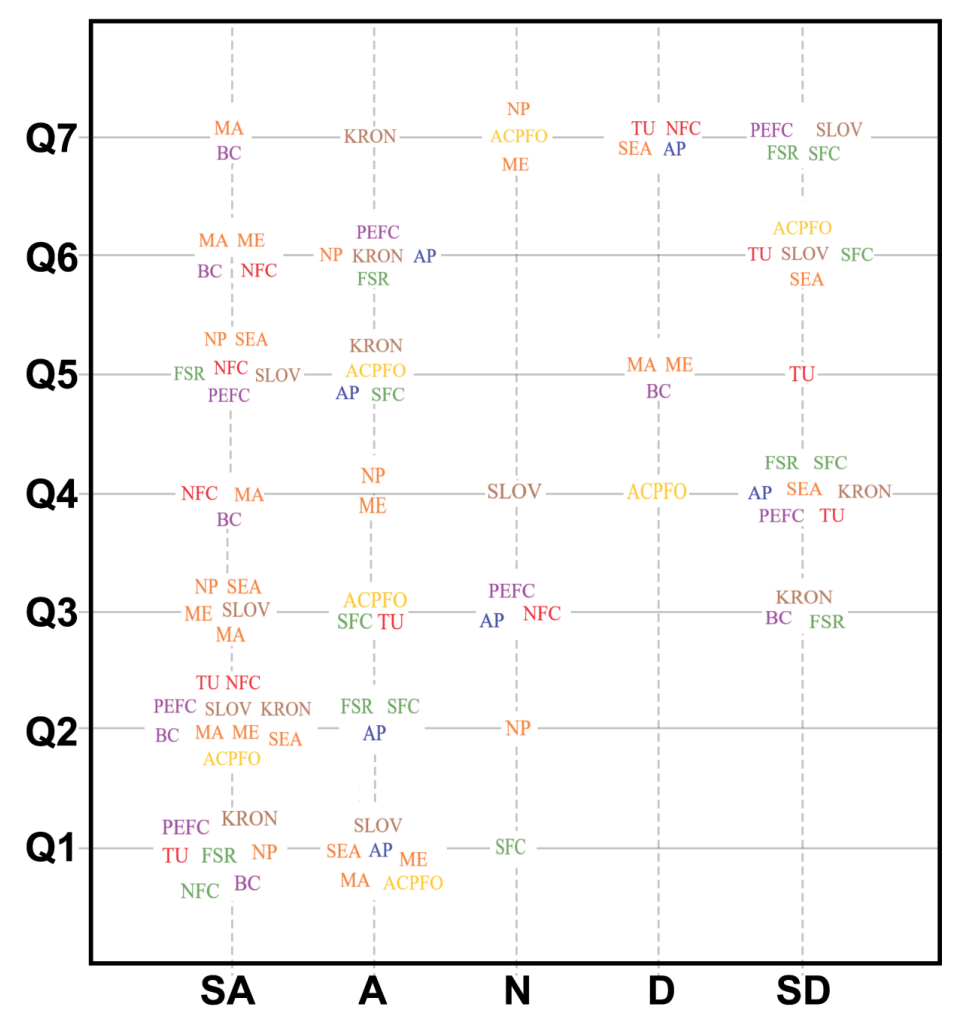

Fig. 1. Summary of respondents' answers (SA - strongly agree, A - agree, $\mathrm{N}$ - neutral, D - disagree, SD - strongly disagree). 
as an opportunity for transformation of forest and woodprocessing sector from a sector based on biomass production to a sector based on knowledge and efficient use of natural resources, while creating a high value added.

The least certain about this are representatives of government and nature protection bodies, which was also confirmed by analysing following question concerning risks that are brought by bioeconomy. Stakeholders from this sector strongly feel that bioeconomy will bring risks for forest and wood-processing sector. The most significant risks according to the interviewed stakeholders appear to be ecosystem degradation emerging from increased use of biomass. Although, biomass is perceived by most of the respondents as a renewable natural resource, there are also contradictory opinions. According to these opinions, it is incorrect to perceive biomass as a renewable natural resource, as biomass production often leads to irreversible damage on forest ecosystems. Also, in alliance with this opinion, increased biomass production for energy purposes is not justified as substitution of fossil fuels, as fossil resources will keep getting used in other industries. Another perceived risks are conflicts between forestry and public, and between individual ecosystem services. The conflict between forestry and public is already quite strong in Slovakia and is supported by static attitudes of nature protection sector, which could potentially jeopardize the source of materials for forest and wood-processing sector. The conflicts between individual ecosystem services emerge mostly in production and non-production ecosystem services, which increased use of biomass could amplify. Also, it is challenging to grasp the transition and increased biomass production so that it will be in line with sustainability principles, which is impeded by inadequate supporting tools e.g. for renewable energy sources.

The most defined perception of bioeconomy-related risks and opportunities have representatives of Kronospan (wood-processing industry) and the Bioeconomy Cluster (non-governmental organisation) followed by the representative of state forests enterprise. These stakeholders strongly agree that bioeconomy will bring new opportunities for forest and wood-processing sector while the biggest risk according to the results is to "not take the opportunity of bioeconomy development". The majority of respondents see that opportunities brought by bioeconomy do not come without its risks. This is the case mostly for governmental bodies, but also for woodprocessing industry, forest university, forest institution and forest owners association. However, representatives of forest and wood-processing sector perceive bioeconomy as bringing more opportunities than risks for these sectors, which is in line with previous studies that proved bioeconomy to be accepted by forest and wood stakeholders (Hodge et al. 2017; Stein 2017). Representatives of government and nature protection, typically, acknowledge that bioeconomy could bring some serious risks, such as over exploitation of biomass, forest degradation etc.
Concerning the involvement in the development of bioeconomy strategy, our results show that majority of our respondents is not involved in these activities. These results are in line with previous research (Davies et al. 2016) stating that stakeholder engagement in participative governance in the area of bioeconomy is unusual. Mostly representatives of governmental bodies claimed to be involved in development of bioeconomy strategy together with non-governmental organisation and forest research. In general, the activities our respondents are involved in are of a sectoral character. Interviewed stakeholders are often member of various working groups on different levels and of different character, e.g. individual regions, ministries, international research projects and initiatives. They are also often active in commenting on various strategies and programmes. Rarely, they also contribute or coordinate development of related strategies (e.g. New Strategy for Sustainable Use of Forest Wealth of Slovakia, National Forestry Programme, etc.) or even a dedicated bioeconomy strategy, that is currently under development.

As most of the forest and wood-processing sector representatives answered previous question negatively, we asked if change in policy framework in forest and wood-processing sector is necessary for it to enhance its participation in bioeconomy development. The majority of our respondents agrees that there is a need for such change, mostly representatives if governmental bodies, forestry (state enterprise) research (National Forest Centre), non-governmental organisation (PEFC) and woodprocessing industry (Slovwood). The perceived need for change emerges from fact that policy framework mirrors societal interests and these interests are progressively evolving and changing through time, therefore policy framework should reflect those changes. The adapted policy framework should according to our respondents promote and support bioeconomy development. What is needed, is a set of complex changes based on addressing several interconnected concepts (bioeconomy, resilience, multifunctionality, governance). There is strong perceived need for cooperation between various sectors, mostly forest and wood-processing sector and nature protection sector, as activities of these sectors are often contradictory. However, the representatives of relevant ministries and forestry university does not agree that a policy framework needs to change. Yet they feel that while change might not be necessary, what is necessary is increasing of funding in these areas together with creating a bioeconomy strategy.

The natural results were obtained when analysing the stakeholders' involvement in negotiating these changes. Representatives of relevant ministries, forest research and even non-governmental organisation (Bioeconomy Cluster) confirmed involvement of their organizations in efforts to negotiate the changes. Stakeholders from forest sector (state enterprise), wood-processing industry (Kronospan), energy counselling and governmental nature 
protection body feel to be partially involved in these activities. Yet, other representatives from forest sector (forestry institution), forest university, wood-processing industry (Slovwood), forest owners association and governmental environmental body do not feel to be involved at all, or if involved, their requests are not being heard.

Finally, the question that has divided our respondents the most concerning the involvement of forest and wood stakeholders in discussions about national bioeconomy development. Representatives of forest sector do not feel to be involved at all or at a very low level into these discussions. The same opinion emerged in areas of energy counselling, wood-processing industry (Slovwood) and governmental environmental body. Representatives of relevant ministry (Ministry of Environment of the SR), forest owners association and governmental nature protection body remain neutral, as they do not feel to have a sufficient knowledge of this problem, therefore their attitude towards the problem would not be accurate. On the other hand, the Ministry of Agriculture and Rural Development and non-governmental organisation (Bioeconomy Cluster) perceive forest and wood stakeholders to be sufficiently involved in national bioeconomy development. As the Slovak national bioeconomy strategy is currently under development, it is interesting to see which sectors are being involved. Ministry of Agriculture and Rural Development together with Bioeconomy Cluster (non-governmental organisation) are working on creating this strategy. Representatives of these two areas also think that forest and wood stakeholders are sufficiently involved in these activities. Yet, the forest and wood stakeholders themselves have a different opinion and most of them doesn't feel to be involved as much as it is needed or even not at all. According to our results, in these activities are also not involved environmental governmental bodies, forest owners association or energy sector.

One of the examples of participatory governance in Slovakia is National Forestry Programme (2007), on development of which participate relevant groups of stakeholders from forest sector and the government. Absence of projects of public-private partnership with participation of stakeholders from forestry and other related sectors is presented as one of the main problems in this document, while it aims to ensure active participation of Slovakia in international initiatives. An updated programme is currently under development. Our results show that when it comes to assessing opportunities and risks connected to bioeconomy development our respondents are quite like-minded. The differences start to occur when assessing the involvement of stakeholders in the development of bioeconomy strategy or even into discussion about national bioeconomy development. Forest stakeholders do not feel to be sufficiently involved in these activities, yet they are more than willing to participate. These results are in line with previous results (Pülzl et al. 2017) stating that forest and wood stakeholders consider the role of their sectors to be crucial for bioeconomy development, yet they are not sufficiently involved in the discussions. As it showed up, they claim that even if they are involved, their voices are not heard. This is confirmed by project BioStep that has identified countries in which participatory governance is very challenging as stakeholders do not feel to be heard (Gerdes et al. 2018) and Slovakia seems to be such country. However, it is necessary to acknowledge the effect that the field of expertise of these stakeholders has on their bioeconomy perception, as this is often the case when analysing stakeholders or experts (Laibach et al. 2019).

The involvement of relevant stakeholders (predominantly in forest sector) is also often analysed through analysis of their power (Agrawal et al. 2008; Brodrechtová 2019). In the case of Slovakia, the highest power have governmental stakeholders in nature protection and forestry followed by non-governmental stakeholders in nature protection and public. Which is in line with our results, as stakeholders that perceived they are engaged in negotiating the policy framework changes are from government and nature protection. On the contrary, on the bottom of this list are stakeholders from recreation and tourism and state forest enterprises (Brodrechtová 2019).

In general, the stakeholders perceive bioeconomy and forest and wood-processing sector within bioeconomy positively. Same results were obtained in study Hodge et al. (2017), in which according to stakeholders, bioeconomy presents an ideal image of the world that societies are trying to develop (Molle 2008). The understanding of bioeconomy by our respondents is quite high, which suggests that bioeconomy discussions in Slovakia are already occurring at least amongst the stakeholders. Bioeconomy, if the chance is taken, is perceived to provide a considerable opportunities for Slovakia in general and for forest and wood-processing sector. However, bioeconomy also brings some risks. The opportunities are acknowledged by almost all of the respondents. Nevertheless, the most afraid of risks are stakeholders from government and nature protection sector.

While our study has the potential to lay groundwork for further bioeconomy research focused on involvement of relevant stakeholders into bioeconomy discussion, it is also affected by some limiting factors. As the first limitation we see the fact that our study is oriented on Slovak stakeholders and mapping the Slovak situation only. However, our results can be seen as an example also for other countries with conditions similar to Slovakia. The second limitation is the number of interviewed respondents. For a more detailed picture of the current situation, further research is needed involving as many stakeholders as possible from all relevant sectors. We consider this study to be a baseline analysis for a subsequent international comparison analysis. 


\section{Conclusion}

Based on our results we can say that transformation towards bioeconomy (also forest-based bioeconomy) is seen amongst the stakeholders as a desirable change, even though according to some respondents, we have been acting (and managing the forests) according to bioeconomy principles for decades without labelling these activities as "bioeconomy". As every concept, bioeconomy presents new opportunities together with risks for forest and wood-processing sector, which are acknowledged by our respondents. However, in stakeholders' perception in general, opportunities prevail. This trend is especially significant within forest and wood stakeholders, while stakeholders from government and nature protection think that some serious risks could be brought by bioeconomy development.

When it comes to the role of forest and wood-processing sector within bioeconomy, there is a need for changing the policy framework in order for it to enhance its position within bioeconomy, according to our respondents. What is also needed, is increasing the funding of this sector and, of course, developing national bioeconomy strategy. Regarding the development of bioeconomy strategy, we find it necessary to improve involvement of not only forest and wood stakeholders, but of all relevant stakeholders from all relevant sectors. That way, we can ensure the cross-sectoral and trans-disciplinary character of the bioeconomy strategy, which is necessary for successful bioeconomy implementation.

In conclusion, Slovak stakeholders perceive bioeconomy and the role of forest and wood-processing sector in bioeconomy (forest-based bioeconomy) to be a great window of opportunities. They perceive the need for bioeconomy development in Slovakia and are willing to participate in creating bioeconomy strategy, but for that engagement processes must be improved creating a participatory governance. The first step in creating a participatory governance should be providing relevant and quality information for public. Our suggestion to this is creating a PR campaign on national level focused on all relevant forestry and bioeconomy issues. In this campaign, experts from all related sectors must be engaged. Next, creating a multi-stakeholder dialogue is needed, which provides an opportunity to share knowledge, insight, possible solutions and to improve decisionmaking process. Further research is however needed, building on our study, to analyse this issue in a more detail and on a bigger scale.

\section{Acknowledgement}

We would like to thank all the respondents whowere kind enough to participate in the study. This publication is the result of the project implementation: FOMON - ITMS 313011V465, supported by the Operational Programme Integrated Infrastructure (OPII) funded by the ERDF. This paper was also elaborated as a part of scientific project VEGA 1/0655/20 "The concept of bioeconomy in the conditions of the Forestry and Wood processing sector in Slovakia".

\section{References}

Aggestam, F., Pülzl, H., Sotirov, M., Winkel, G., 2017: The EU policy framework. In: Winkel, G. (ed.): Towards a sustainable European forest-based bioeconomy- assessment and the way forward. European Forest Institute, Joensuu, p. 19-35.

Agrawal, A., Chhatre, A., Hardin, R., 2008: Changing governance of the world's forests. Science, 320:1460-1462.

Bell, J., Paula, L., Dodd, T., Németh, S., Nanou, C., Mega, V. et al., 2018: EU ambition to build the world's leading bioeconomy-Uncertain times demand innovative and sustainable solutions. New Biotechnology 40: 25-30.

Bezama, A., 2018: Understanding the systems that characterise the circular economy and the bioeconomy. Waste Management and Research, 36:553-554.

Böcher, M., Töller, A. E., Perbandt, D., Beer, K., Vogelpohl, T., 2020: Research trends: Bioeconomy politics and governance, Forest Policy and Economics, 118:102219.

Brodrechtová, Y., Navrátil, R., Sedmák, R., Tuček, J., 2018: Using the politicized IAD framework to assess integrated forest management decision making in Slovakia. Land Use Policy, 79.

Brodrechtová, Y., 2019: Aktéri a ich moc pri obhospodarovaní lesov Slovenska - empirická analýza a poznatky z regiónu Podpol'ania. Zvolen, Vydavatel'stvo TU vo Zvolene.

Davies, S., Griestop, L., Vironen, H., Bachtler, J., Dozhdeva, V., Michie, R., 2016: Case studies of national bioeconomy strategies in Finland and Germany. In: BioSTEP Promoting stakeholder engagement and public awareness for a participative governance of the European bioeconomy. $56 \mathrm{p}$.

Gerdes, H., Kiresiewa, D. Z., Beekman, V., Bianchini, C., Davies, S., Griestop, L. et al., 2018: Engaging Stakeholders and Citizens in the Bioeconomy: Lessons Learned from BioSTEP and Recommendations for Future Research. In: BioSTEP Promoting stakeholder engagement and public awareness for a participative governance of the European bioeconomy, $56 \mathrm{p}$.

Hodge, D., Brukas, V., Giurca, A., 2017: Forests in a bioeconomy: bridge, boundary or divide? Scandinavian Journal of Forest Research, 32:582-587.

Kircher, M., Breves, R., Taden, A., Herzberg, D., 2018: How to capture the bioeconomy's industrial and regional potential through professional cluster management. New Biotechnology, 40:119-128. 
Kleinschmit, D., Arts, B., Giurca, A., Mustalahti, I., Sergent, A., Pulzl, H., 2017: Environmental concerns in political bioeconomy discourses. International Forestry Review, 19:41-55.

Laibach, N., Borner, J., Broring, S., 2019: Exploring the future of the bioeconomy: An expert-based scoping study examining key enabling technology fields with potential to foster the transition toward a bio-based economy. Technology in Society, 58:101-118.

Lazdinis, M., Carver, A., Schmithüsen, T., Tõnisson, K., Vilkriste, L., 2005: Forest-sector concerns in the Baltic States: implications for an expanded European Union. Society \& Natural Resources, 18:839-848.

McCormick, K., Kautto, N., 2013: The Bioeconomy in Europe: An overview. Sustainability, 5:2589-2608.

Navrátilová, L., Výboštok, J., Dobšinská, Z., Šálka, J., Pichlerová, M., Pichler, V., 2020: Assessing the potential of bioeconomy in Slovakia based on public perception of renewable materials in contrast to nonrenewable materials. Ambio, 49:1912-1924.

Navrátilová, L., Giertliová, B., Hajdúchová, I., Šálka, J., 2021: Acceptance of bioeconomy principles in strategic documents on European and Slovak level. In: SHS Web of Conferences, 92:02044

Paluš, H., Krahulcová, M., Parobek, J., 2021: Assessment of Forest Certification as a Tool to Support Forest Ecosystem Services. Forests, 12:300.

Parobek, J., Paluš, H., Moravčík, M., Kovalčík, M., Dzian, M., Murgaš, V. et al., 2019: Changes in carbon balance of harvested wood products resulting from different wood utilization scenarios. Forests, 10:590.

Pülzl, H., Giurca,A., Kleinschmit, D., Arts, B., Mustalahti, I., Sergent, A. et al. 2017: The role of forests in bioeconomy strategies at the domestic and EU level. In: Winkel, G. (ed.): Towards a sustainable European forest-based bioeconomy - assessment and the way forward, Joensuu, European Forest Institute, p. 36-51.
Sarvašová, Z., Šálka, J., Dobšinská, Z., 2013: Mechanism of cross-sectoral coordination between nature protection and forestry in the Natura 2000 formulation process in Slovakia. Journal of environmental management, 127:65-72.

Stein, M., 2017:Die Bedeutung der Bioökonomie für den deutschen Forst- und Holzsektor Untersuchung der Wahrnehmung und Akzeptanz für das Thema Bioökonomie von Akteuren aus dem Forst- und Holzsektor. University of Freiburg in German.

Zeug, W., Bezama, A., Moesenfechtel, U., Jähkel, A., Thrän, D., 2019: Stakeholders' Interests and Perceptions of Bioeconomy Monitoring Using a Sustainable Development Goal Framework. Sustainability, 11:1511.

Wolfslehner, B., Linser, S., Pülzl, H., Bastrup-Birk, A., Camia,A., Marchetti, M., 2016: Forest bioeconomy-a new role for sustainability indicators. From Science to Policy, 4:32.

\section{Other sources}

European Commission. 2018. A sustainable Bioeconomy for Europe: strengthening the connection between economy, society and the environment. Brussels. https://doi.org/10.2777/478385

German Bioeconomy Council. 2018. Update Report of National Strategies around the World-Bioeconomy Policy (Part III); Bioeconomy Council: Berlin, Germany.

Ministry of Agriculture and Rural Development of the Slovak Republic, National Forest Centre. 2007. National Forestry Programme.

RStudio Team (2020). RStudio: Integrated Development for R. RStudio, PBC, Boston, MAURL http://www. rstudio.com/. 